\title{
Land use and travel behaviour: expected effects from the perspective of utility theory and activity-based theories
}

\author{
Kees Maat \\ OTB Research Institute for Housing, Urban and Mobility Studies, Delft University of Technology, \\ PO Box 5030, 2600 GA Delft, The Netherlands; e-mail: c.maat@otb.tudelft.nl

\section{Bert van Wee} \\ Faculty of Technology, Policy and Management, Delft University of Technology, PO Box 5015, \\ 2600 GA Delft, The Netherlands; e-mail: g.p.vanwee@tbm.tudelft.nl
}

\section{Dominic Stead}

OTB Research Institute for Housing, Urban and Mobility Studies, Delft University of Technology, PO Box 5030, 2600 GA Delft, The Netherlands; e-mail: d.stead@otb.tudelft.nl

Received 27 July 2003; in revised form 22 September 2004

\begin{abstract}
Assumptions about the effects of various land-use characteristics on travel patterns have found their way into diverse concepts of planning and design, such as the compact city and neighbourhood-design principles. In general, these concepts aim at reducing travel distances and reducing car-travel speed, as it is assumed that as travel distances are shorter, individuals will travel less, and the relative competitive position of slower modes is increased. Although some literature supports the link between land use and travel behaviour, for the greater part limited effects have been concluded, whereas in others it has been concluded that there is virtually no effect. We argue that the effects fall short of the expectations advocated by the land-use concepts, because of shortcomings behind assumptions concerning the relationships between land use and travel behaviour. We argue that utility-based and activity-based theories add some extra insights. Various behavioural responses in terms of travel-time changes are possible, depending on whether travel time is minimised, benefits maximised, or activity patterns optimised. It is concluded that the contribution of compact urban designs to reduction on travel may not be as straightforward as is suggested by their advocates. In any case, a simplified distance-oriented and trip-oriented approach is unable to examine complex behaviour, and a broader framework of space and time is needed.
\end{abstract}

\section{Introduction}

Travel enables people to participate in societal and economic activities, but it is also associated with a loss of accessibility because of congestion and parking problems as well as with adverse externalities, including impacts on safety, the environment, and health. Many of these externalities are increasing in line with the growth in transport, despite the introduction of a variety of measures to address these problems. In addition, the growth in transport demand is taking place in the modes with high externalities, such as cars and aircraft. In the past, authorities have responded to the rising demand for travel by investing in infrastructure, in particular by increasing road and parking capacity (Banister, 2002). Gradually, however, policymakers have come to realise that many improvements are only temporary, as they may generate more traffic (Goodwin, 1996), and that new car infrastructure does not solve environmental problems. Conversely, solutions that reduce environmental damage, in particular technological solutions, do not solve congestion problems. These realisations have prompted a new response to the irrepressible demand for travel, sometimes called 'new realism', which attempts to reduce car travel—or at least its growth (Banister, 1997; Fullerton, 1998).

Among the strategies to reduce car travel, the idea of influencing land use seems plausible, as the spatial structure of housing, employment, services, and leisure forms the context within which people travel. Moreover, the empirical background for this 
assumption is derived from developments in the past. The increase in car travel, first in the United States and, after World War 2, also in Europe, has occurred hand in hand with the dispersal of housing, work, and leisure, the thinning out of the city, and the urbanisation of rural areas. Rising prosperity brought the car and low-density suburban living within the reach of many people. The suburbanisation of housing was followed by the dispersal of employment, both of which were facilitated by transport and infrastructure. The resulting spatial form increased the need to travel. Moreover, it favoured the car, as the increased distances discouraged travel on foot or by bicycle, and the decreased densities proved to be too low for public transport. Furthermore, the scattered urbanisation pattern encouraged dispersed travel patterns, which are not easily served by public transport. Consequently, it would seem plausible to assume that a reversal of this situation, by compacting urbanisation, densification, and mixed-use development, will reduce the need to travel-in particular by car (see, for example, Calthorpe, 1993; CEC, 1990; CNU, 1998; DETR, 2001; Katz, 1994; Ministry of VROM, 1991).

There is a growing body of research concerned with the relationship between urban form and travel patterns. Studies originate from a diversity of sources, and encompass a variety of geographic scales and locations. To add to this diversity, many different characteristics of urban form have been examined in these studies, and travel patterns have been measured in a number of different ways. Some of this research supports the view that various aspects of land use are linked with travel patterns or travel behaviour (for example, Banister, 1997; Cervero and Kockelman, 1997; Ewing, 1995; Frank and Pivo, 1994; Meurs and Haaijer, 2001; Næss and Sandberg, 1996; Newman and Kenworthy, 1989; Stead, 2001), although in most of this literature only limited effects have been found. In addition, the evidence is not always consistent, and for every piece of empirical evidence demonstrating a link between urban form and travel patterns a counterclaim can almost always be found. This has brought some authors to the conclusion that most of this body of research suffers from methodological flaws, and that the precise nature of these relationships, and how they work, is often unclear from the research. Therefore, they have applied more sophisticated methods, but they have also reported lower effects than others, or have concluded that there is virtually no effect at all (for example, Bagley and Mokhtarian, 2002; Boarnet and Sarmiento, 1998; Crane and Crepeau, 1998; Kitamura et al, 1997; Schwanen, 2003; Snellen et al, 2001). For overviews of the literature, readers are directed to Ewing and Cervero (2001), Handy (1996), Stead and Marshall (2001) or, for a review of Dutch studies, van Wee and Maat (2004).

One of the reasons that the effects fall short of the expectations of advocates of compact urban design is that the assumptions behind travel behaviour have some shortcomings. It is expected that, because of the reduced distances between locations and an increased population base for public transport, travel distances will be reduced and mode choice shifted towards nonmotorised and public transport. However, such assumptions ignore other aspects of travel demand, as can be derived from utility and activity-based theories. For example, there is rarely mention of how people might use their 'spare' time if journey distances and times are reduced because of land-use changes, or what new travel patterns may occur within households if one member finds it more convenient to use public transport in place of the car because of improvements in access to public transport.

In this paper we demonstrate that the introduction of assumptions which are derived from utility theory and activity-based theories leads to assumptions about the relationship between land use and travel patterns other than those which traditionally underly the concepts of compact designs. The structure of this paper is as follows. 
First, concepts of planning and design are introduced. Next, some of these shortcomings are examined, and we then discuss how, given the theoretical assumptions, people may respond to the spatial concepts. Finally, some conclusions are drawn.

\section{Concepts of planning and design aimed to influence travel behaviour}

Assumptions about the effects of various land-use characteristics on travel patterns have found their way into diverse concepts of planning and design. Many different land-use characteristics have been included in these concepts, ranging from regional to local to neighbourhood scales. At the regional level, this involves the location of new development in relation to existing towns, cities, and other infrastructure, and the size and shape of new development, and the type of land use. At the local level, land-use concepts concern the level and scale of land-use mixing, density, and the extent to which development is clustered or concentrated into nodes. At the neighbourhood scale, notions on land use are concerned with urban design and movement networks, such as pedestrian-friendly and bicycle-friendly design and local services and facilities. Various land-use concepts that attempt to influence travel patterns are described below, each relating to different scales of urban form.

\subsection{The scale of cities and urban regions: the compact city and the jobs - housing balance}

In Europe the notion of the 'compact city' has received attention from some individual countries and from the European Commission as a way of improving the urban environment and reducing car dependence at the national or regional scale. According to the European Commission, the dispersal of home, work, and leisure facilities entails an increasing need to travel, which implies that such trends need to be restrained. For that purpose, the Commission promotes the concept of the compact city and highlights the role of high urban population densities and mixed-use development. These measures, according to the Commission, should reduce the number of car-travel kilometres and improve the share of trips made by bicycle and public transport (CEC, 1990). The 2001 European transport white paper identifies urban and land-use planning policy as being able to "avoid unnecessary increases in the need for mobility caused by unbalanced planning of the distances between home and work" (CEC, 2001, page 6).

The Netherlands is a good example of a country where the compact-city policy is not only included in national spatial planning policies, but is also implemented in many cities. Spatial planning policies have aimed to influence travel behaviour here since the 1960s, and the concept of the compact city became a basic principle of urban planning in the 1990s (Ministry of VROM, 1991). This strategy aims to reduce urban sprawl, and implies intensive land-use patterns and a predominantly monocentric structure at the level of urban regions, where residential, employment, and service functions are operating at the level of the city region. To achieve this, concentration at the urban regional level has been a major element in the Dutch compact-city concept. Instead of a dispersed urbanisation pattern, new housing developments were required to be sited within, adjacent to, or in the vicinity of the central cities. Compact designs were encouraged, with relatively high densities and mixed uses. Industries, offices, or services with a high intensity of use by personnel or visitors were required to be established at locations accessible by public transport. More recently, however, it has been argued that the process of urban sprawl is consistent with a transition to a multinucleated form (Dieleman and Faludi, 1998), which makes it difficult to implement the monocentric-oriented compact-city policy as a means of controlling mobility. The Dutch government now plans to introduce an adaptation of the concept, the so-called notion of 'urban networks', which aims at concentrating new work 
and housing developments near to existing and potential public transport nodes and motorway intersections (Ministry of VROM, 2004).

The attention to concentration on a regional scale brings to mind the jobs - housing debate in the United States in the late 1980s. The debate focused on two issues. First, it was found that suburban communities were fundamentally unbalanced, meaning that the amount of suitable housing differed substantially from the amount of employment, thus generating additional car traffic. In other words, the spatial distribution of employees differed strongly from the spatial distribution of jobs. Second, regardless of this spatial distribution, there was excess travel (sometimes referred to as 'wasteful commuting') because, with a better fit between the locations of employees and jobs, average travel distances and times could be much smaller. However, the extent to which this was really true depends upon assumptions about segmentations of the labour and housing markets as well as on temporal friction between job vacancies and job seekers (see, for example, Cervero and Wu, 1997; Hamilton, 1982; 1989; Modarres, 2003; White, 1988). For the debate on the compact city, two aspects of the discussion are relevant. To prevent spatial mismatch, proponents of jobs-housing balancing have suggested that houses, shops, and jobs need to be built close to each other, preferably at the local level or at least at the regional level ('balancing'), so that commuting distances can be shortened. In order to achieve this, strictly separated land uses need to be exchanged for mixed-use development. Others found indications for the colocation hypothesis in that, over time, decentralised housing development is followed by decentralised employment (Giuliano and Small, 1993). It is clear that a strong mismatch between the locations of jobs and houses results in much forced commuting over longer distances. However, even if jobs and houses are spatially balanced, this does not guarantee that people will choose jobs near their residential location, or that people will choose a house near their work. According to Redmond and Mokhtarian (2001), many people like a commuting distance of around 15 to 20 minutes, and do not try to minimize their commuting time below this. Even if the overall number of employees and the related number of houses in a certain area is the same as the number of jobs, there is not guarantee that there will be a match between these jobs and these workers.

\subsection{The neighbourhood scale: layouts for slow modes and new urbanism}

It is assumed in concepts of urban design that the layout of urban areas at the neighbourhood level can also influence the travel patterns, by affecting the attractiveness of different modes of transport. For example, car use can be discouraged through designs that reduce vehicle speeds (and therefore increase travel time), such as trafficrestraint measures (for example, speed humps or indirect ingress or egress routes), or designs that reduce the availability of parking. On the other hand, the use of slow modes, such as cycling or walking, can be encouraged through the provision of facilities for these modes and dedicated, direct routes. In addition, reducing the speed of cars can make travel by slow modes safer and more convenient. In terms of public transport, increases in development density near public transport stops is assumed to increase potential ridership. However, there is a more complex relationship: better access to public transport potentially encourages more travel, as well as potentially reducing car travel. On the other hand, with better access, public transport also competes with slow modes.

The success of the bicycle-friendly design of the new town of Houten, near the city of Utrecht in the Netherlands, is an example of this type of land use. This layout provides a direct railway service to Utrecht, a shopping centre and offices near the railway station, and all residential neighbourhoods within approximately 1.5 kilometres (cycling distance) of the town centre. A dense network of comfortable cycle routes 
connects the town centre and all neighbourhoods together, and through traffic by car is discouraged by being forced to use a ring road outside the built-up area (see also Maat, 2001).

The focus on designed communities is also seen in the so-called 'new urban designs' in the USA, such as pedestrian pockets, neotraditional design, and transitoriented design - collectively known as 'new urbanism'. Advocates of these designs (for example, Calthorpe, 1993; Ewing, 1995) support a return to more traditional and urban-style development, that is: the creation of diverse, compact, and mixed neighbourhoods. Everyday activities, such as housing, work, schools, shops, and other amenities, are all ideally within 10 minutes' walking distance of each other. The aim is to provide a pleasant, comfortable, interesting, and safe environment for pedestrians, and to provide alternatives to car use - such as public transit and cycling facilities. A grid network and higher densities provide short walking access (CNU, 1998). "Together these strategies may reduce driving not only by encouraging alternatives - walking, biking, and transit-but also by reducing the distances that residents drive when they still get in their cars" (Handy and Clifton, 2001, page 318).

\section{Theoretical perspectives on travel demand}

In section 2 we suggested that there are a number of concepts of planning and design aimed at reducing car-travel kilometres. Car-travel reduction can be achieved through three strategies: (1) by mode shifting from car to walking, cycling, and public transport; (2) by reducing trip distance; and (3) by reducing the total number of trips. What the land-use concepts outlined above have in common is that they seek to reduce travel distances and to increase the share of public transport by increasing the population base for public transport. Situating residential, employment, and service locations closer to each other is generally assumed to reduce the distances which need to be covered. It is expected that the shorter travel distances will result in a reduction in the total number of kilometres travelled, an increase in the possibility of linking more destinations in one trip ('trip chaining'), and an increase in the attractiveness of walking and cycling in place of using the car. Higher densities are assumed to improve public transport use because distances to public transport stops are shorter.

It is assumed that, when nearby destinations are added to the choice set, average travel distances tend to get shorter because these destinations will be chosen rather than more distant ones. Moreover, as travel distances are shorter, individuals are assumed to be more likely to choose to travel by foot or by bicycle.

Although these are plausible assumptions, when other considerations are considered, the picture changes (see also Boarnet and Crane, 2001). One shortcoming is the single focus on the costs of travel, and not on the benefits. The theoretical foundation of travel demand can be found in the notion that most travel is derived from the need of individuals and households to participate in activities and, as they cannot all be conducted at the same location, travel is necessary. Participation in activities thus yields benefits and costs. As we know from utility-based theories on travel demand, individuals are assumed to make choices in which they maximise the utility they obtain by participating in an activity. This utility is the trade-off between the benefits (or net utility, which is the positive part of the utility) and the costs (or disutility) to bridge the distance to an activity location. Whereas the land-use concepts seem to emphasise the costs, the utility perspective also enters the benefits into the equation. For example, in choosing a shopping destination, the positive part of the utility is the attractiveness of the shop-such as choice or quality-whereas the disutility part is the cost of getting there. Thus, individuals may maximise their utility by opting for a more distant destination in order to get higher quality, greater choice, or cheaper products. 
Second, individuals are not primarily interested in travel distance, but, rather in the costs of bridging that distance: namely, time, money, and effort. In particular, time is seen as a significant factor as an individual's available time is a scarce resource (see, for example, Gonzales, 1997; Pas, 1998). Thus, individuals may choose a more distant destination if it can be reached in less travel time.

Third, in the traditional approach, trips are considered. In doing that, however, one loses sight of the broader picture within which travel decisions are made. From the perspective of travel as a derived demand, one would assume that such choices need to be considered within an integrated framework of activity participation (Golob, 1998). This is the basis of the activity-based approach, which assumes that people do not make separate decisions considering only trips, but that they try to schedule activities in a daily pattern. As a consequence, a fundamental difference between the trip-based approach and the activity-based approach is the way in which time is conceptualised and represented. In the trip-based approach, time is reduced to being simply a 'cost' of making a trip. The activity-based approach, on the other hand, treats time as an all-encompassing continuous entity within which individuals make activity and travel decisions (Bhat and Koppelman, 1999). Activity participation can thus be seen as a matter of time allocation (Pas, 1998), which means that individuals do not maximize utility for separate travel choices, but that they optimize their entire activity pattern.

Fourth, closely related to the previous point is the unrealistic assumption that individuals are free to choose the alternative they like best. Advocates of the constraint approach, however, propose that activity and travel are not only based on utilitymaximising choices, but that they are also constrained by space, time, and the institutional context (Axhausen and Gärling, 1992; Timmermans, 2000). Hägerstrand's time geography (1970) showed that both space and time are scarce resources and constrain daily activity patterns. Such constraints relate to the amount of physical time in a day and the time required for personal care, eating, and sleeping, and the necessity to perform some activities, such as work, at a fixed place, at a certain time, and over a fixed duration. Other constraints include, for example, interdependencies between household members that determine daily activity schedules (for example, common activities such as eating).

Constrained time budgets also imply that time spent travelling cuts into the time available for other activities, thus limiting activity demand. This mechanism is termed the 'time-budget effect' (see, for example, Golob, 2000). There are two hypotheses in time-budget research, which assume that time budgets are either fixed or flexible (see Kraan, 1998, for an overview). In the fixed travel budget approach, at an aggregate level, such as for a whole country, total travel time is considered as more or less constant (Schafer and Victor, 2000; Zahavi, 1979). Savings in travel time, achieved by travelling over shorter distances or by using faster modes, are allocated to other travel, resulting in more and longer trips. This implies that reducing distances by means of more compact land-use concepts induces the choice of more remote destinations, and thus longer travel times, or a shift to slower modes. Conversely, in the flexible travel budget approach, the time saved on travel can be allocated to other activities as well. Note that the assumption of constant travel time budgets is not consistent with utility theory, as there is no reason for an exact constancy. For example, assume all circumstances remain the same except for travel costs being reduced. This is likely to result both in an increase in travel and in an increase in travel time per person, according to utility theory. However, though exact constancy in travel time cannot be expected according to utility theory, a more or less stable average travel time per person could be expected at an aggregate level. One reason is that a person with a very short travel time might obtain a relatively strong increase in utility as a result of additional travel, but the more he or she travels, the lower the additional utility. Therefore, according to 
utility theory, it is unlikely that, on average, people will hardly travel at all, but it is also unlikely that, on average, people will travel two or three hours per day: the additional utility compared with less travel is low, but the additional costs are high. Another reason is that people prefer to travel for a certain time each day than not to travel or hardly to travel at all (Redmond and Mokhtarian, 2001).

In addition, the relative positions of locations determine spatial constraints. These constraints include the amount of travel needed, the feasible distances which can be covered, and even the possibility of engaging in activities (Kraan, 1998). A spatial environment that provides high accessibility to facilities may increase people's involvement in activities.

To summarise these theoretical notions, it is assumed that people attempt to meet their basic needs within constraints of space and time and in the context of the household and institutions, while performing trade-offs between utility and cost. As a consequence, an individual's aim is not primarily to minimise travel costs, but, rather, to maximise utility. Saved time can be consumed by increases in activity time, but also by the substitution of more preferred destinations that entail higher travel costs (in order to obtain a higher attractivity), or by scheduling more out-of-home activities. The last two options would lead to increased travel. This effect is often called 'latent' travel demand (Golob, 1998). In the next section, the notions mentioned above are used to hypothesise the effects of spatial features on activity and travel behaviour.

\section{Behavioural responses to travel-time changes}

\subsection{Introduction}

In this section the theoretical assumptions discussed above are used to deduce the outcomes that can be expected from the concepts of spatial planning and design, focusing specifically on two aspects of urban form-density and mixed use. As is evident from the foregoing discussion, it is assumed that the influence of urban form mainly runs through travel time. The simple model in figure 1 illustrates this, with net utility as a function of travel time. Net utility includes all the benefits people gain from the activity, whereas disutility is represented by travel time.

The figure shows a given travel time $T_{1}$, with a given net utility, $U_{1}$. The utility is, by definition, positive, otherwise one would not spend travel time. It is assumed that utility increases with the travel time spent, otherwise one would not spend more time travelling. The further one travels, the more opportunities are within reach and the bigger the chance of being able to reach an opportunity with a higher utility. Furthermore, it is assumed that the curve is S-shaped. The first part of the trip is used in some

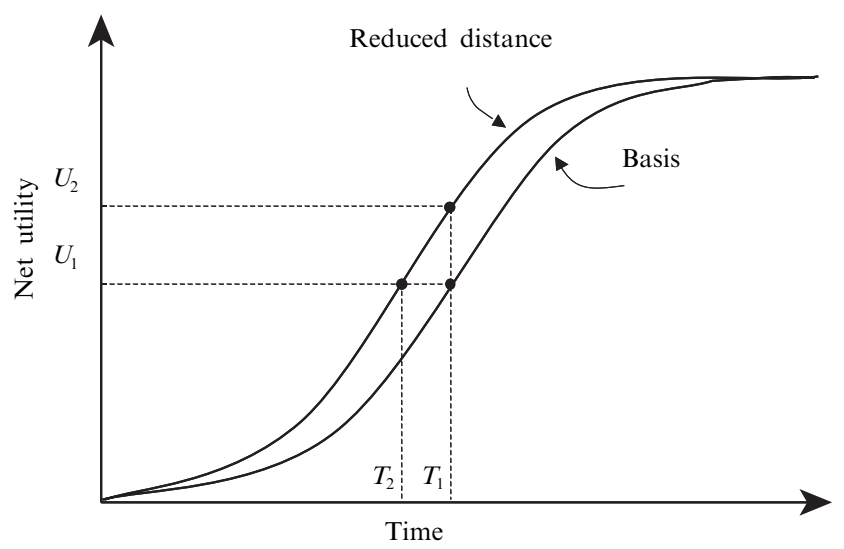

Figure 1. Stylised effects of travel-time changes. 
initial actions, such as walking to the car, starting the engine, or unlocking the bicycle, so hardly any benefit can be expected. Then, utility increases. Third, it is assumed that the increase of utility slows down with increase in travel time because the additional benefits of travelling longer might be subject to the law of diminishing returns. For example, the second-nearest supermarket might be more attractive than the nearest, perhaps because of lower prices or more variety in products, but the additional benefits of the fifth-nearest compared with the fourth-nearest might be smaller. (Note that the curve would have been bell shaped if distance was displayed, as initial actions do not affect travel distance.)

Travel time is dependent on travel distance and travel speed. The model illustrates the consequences for changes in travel distance and speed on the relationship between travel time and utility. The additional curves address the effects of shorter distances and reduced speeds on utility, as can be expected in compact urban designs. The rationale is as follows: if distances are shorter, utility is higher (assuming the same travel time), or travel time is shorter (assuming the same utility). For lower speeds, the effect is the other way around: one has to travel longer for the same utility (horizontal line) or obtains a lower level of utility from the same travel time (vertical line). Note that as travel time increases the curves get closer and eventually come together.

It should be noted here that, in the reasoning above, it is assumed that utility (for each activity type) is equally spread. However, uses are rarely perfectly mixed, so utility and travel time will change discontinuously. Figure 2 displays two utility curves. They are found by sorting locations by ascending travel times, where only locations which have a higher utility than the closer ones are displayed (see van Wee et al, 2001). If uses are mixed, it becomes more likely that shopping needs can be satisfied in the immediate vicinity of the home. To receive some extra utility, a little amount of extra travel time is needed. However, if uses are concentrated, for example in a large commercial centre at the edge of the city, a larger amount of time may be needed to reach the nearest supermarket, but with only a little amount of extra time the other supermarkets are reached. This explains the importance of considering the type of activities that can be spatially mixed or concentrated. For example, mixing supermarkets can actually result in shorter average travel times because the added value of a third or fourth supermarket is very small; many people will choose the nearest or second nearest supermarket for daily shopping. However, mixing jobs is unlikely to result in shorter travel times because the chance that the job with the highest net utility (utility of the job minus the disutility of travel) is nearer, because of the mixed job pool, is quite small. The same holds for specialised shops with a regional, or even larger, catchment area.

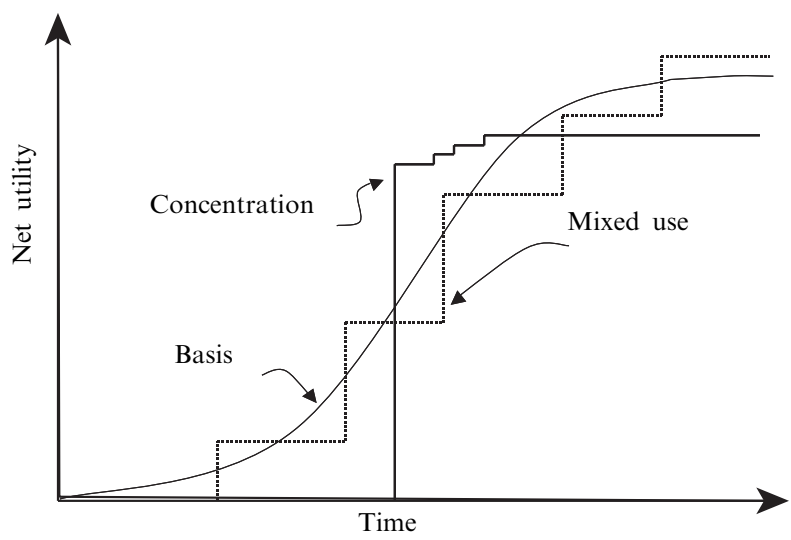

Figure 2. Stylised effects of mixed use. 


\subsection{Effects on frequency and distance travelled}

The effect displayed in figure 1 shows a situation in which travel distances between locations are reduced, as may be expected in compact urban designs. Three types of behavioural response are possible. First, if one aims only at minimising travel time, and thus utility, $U_{1}$, remains unchanged, shorter distances will reduce travel times to $T_{2}$. Trip frequency may also decrease because trip chaining is more likely with shorter distances. Let us assume, for example, individual A, living in a remote suburb with a supermarket within 10 minutes' travel time. Another individual, B, living in a compact town, has a similar shop within 5 minutes' travel time. Hence it can be seen that compact urban designs offer the opportunity to travel less.

However, let us now consider individual B, living in the compact town. Although there is a supermarket within 5 minutes' travel time, there is also a cheap and large hypermarket in the city centre-within 10 minutes' travel time. If an individual aims to maximise utility, and thus accepts travel time $T_{1}$, no distances are reduced, but the higher utility, $U_{2}$, is obtained. This means that the potential travel-time savings are used for longer trips to get extra, latent, utility.

Third, if one reduces travel time towards $T_{2}$, and travel-time savings are not used for extra utility farther away (and thus remain as $U_{1}$ ), more activity time is left $\left(T_{1}-T_{2}\right)$ - which can be allocated to engage in other activities, either in the home or outside. Out-of-home activities may increase the number of trips, and consequently the kilometres travelled. In this option, not only the trip itself is considered, but it is also assumed that individuals consider their entire activity pattern, and thus may attempt to adapt their daily pattern by allocating additional time to activities with a lower priority. Evidence for such latent travel demand can be found in the work of Golob (1998; 2000): He found that time saved thanks to trip chaining was used for other activities, and that the time saved with shorter commuting times was used for other out-of-home activities.

Another effect (not displayed in figure 1) concerns the effect of reduced speeds on utility, speed reduction may be aimed at traffic calming, for instance in pedestrianfriendly and bicycle-friendly designs. Moreover, in compact designs, concentration and densification may unintentionally lead to more congestion and longer searching times for a parking space, and thus to lower average speeds. Because lower speeds increase travel times, the effects are mainly opposite to the effects of distance reduction. However, because travel reduction is targeted mainly at cars, effects on modal choice can be expected as discussed in the next section.

\subsection{Effects on mode choice}

Travel distance may change the relative cost of each mode, and thus also influence mode choice. Figure 3 (over) displays the relationship between utility and travel time for different modes. Pedestrians have hardly any initial actions, their average speed is low but constant, and, because of the physical effort involved, their maximum travel time is limited. Bicycles have higher speeds, so more utility is obtained with the same travel time. The curve for cars is strongly S-shaped. The figure shows that at a certain distance, the likelihood of choosing a certain mode changes. On the basis of travel time, the maximum utility for pedestrians and cyclists is reached at times $T_{1}$ and $T_{2}$, respectively.

Figure 3 also displays the effect of speed reduction for cars, such as might be expected in pedestrian-friendly or bicycle-friendly designs (or the US new urban designs). Although traffic lights and road designs may also reduce speeds for slow modes, traffic-calming measures are mainly targeted at car use. In fact, artificially extending distances for cars and slowing down car speeds in pedestrian-friendly and bicycle-friendly designs will extend car-travel costs-which makes walking and cycle 


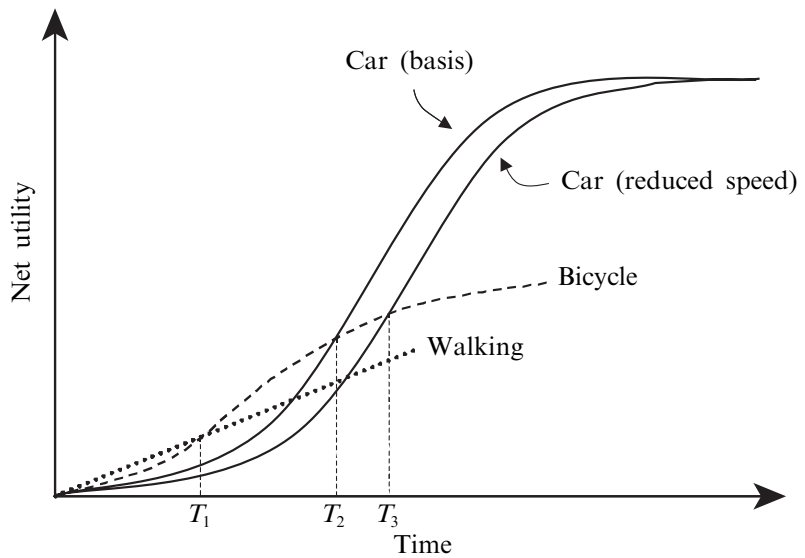

Figure 3. Stylised effects of mode changes.

routes relatively more attractive. As a consequence, speed reduction for cars increases the likelihood of a change to slow travel modes. Hence, shorter distances encourage people to walk or cycle, relative to the use of motorised modes such as cars and public transport. However, as traffic calming and congestion are features mainly of urban areas, speed reduction occurs mainly over shorter distances. Consequently, after a certain distance, the curves become parallel. It may be concluded here that speed reduction for cars seems to reduce car travel from the perspective both of utility-based and of activity-based theories.

\subsection{Additional comments}

Three additional comments are warranted. First, because individuals maximise their utility, an increase in travel time is associated with an increase of the utility of an activity. However, this relationship is not necessarily linear. With a homogeneous distribution of activities over space, a doubling of travel time (assuming constant speeds) can potentially result in four times as many activities being within reach. However, the increase in activities is subject to the law of diminishing returns: the increase in utility of being able to choose between six supermarkets instead of five, for example, means a lower increase of utility than an increase from one or two supermarkets. The relationship between utility and travel time is further complicated because of the nonlinear relationship between time and distance. On average, speeds increase if average travel distance and travel time increase because of the larger proportion of faster roads being used. An additional complication is the nonlinear value of time (see section 2.1), which may also vary by trip purpose. Thus, in practice, some of the lines in figure 2 may have a different shape but the general pattern is likely to be similar and, generally speaking, there will be an increase in utility if travel distance increases. In the figure we have assumed that disutility is caused only by travel time, but we recognise that there are, of course, other types of disutility associated with different modes (for example, monetary costs, different levels of comfort, or the ability to carry out other activities during the journey). It should also be noted that, although the intersection of utility lines for different modes can be at a given point in space (for example, a destination which has an equal travel time for more than one mode), this does not necessarily have to be the case (for example, two separate destinations can provide the same level of utility). Second, car trips take less time if roads suitable for higher speeds can be used, even if distances are longer. Travel times for public transport are dependent on the quality of the connection, including frequency, transfers, access, and egress. Thus, from the perspective of travel-time reduction, shorter distances compete 
with faster modes and faster routes. This means that it might be an option for car drivers to choose another destination to obtain lower travel costs. Third, other costs, such as differences in effort for certain purposes, may change the likelihood of walking or cycling dramatically: for example, the necessity to carry goods or children. This may also vary with health or age. Moreover, personal preferences, for instance, a strong preference for the car, may weaken this (van Wee et al, 2002).

\section{Conclusions}

Among the strategies for reducing car travel, the idea of influencing land use seems an attractive one as the spatial structure of housing, employment, services, and leisure forms the context within which people travel. The increase in car travel has occurred hand in hand with urban sprawl. Consequently, it would seem plausible to assume that a reversal of this relation by compact urbanisation, densification, and mixed-use development, will reduce the need to travel - in particular by car. Such assumptions have found their way into diverse concepts of planning and design, such as the compact-city and neighbourhood-design principles.

In general, these concepts aim at reducing distances, as it is assumed that, when travel distances are shorter, individuals will travel less, and be more likely to choose walking or cycling. Furthermore, neighbourhood designs offer lower car-travel speeds which increase the relative competitive position of slow modes. Moreover, higher densities, especially near railway stations and other public transport stops, provide a better population base for public transport support.

There is a growing body of research concerned with the relationship between land use and travel patterns. Some of this research supports the link between land use and travel behaviour; however, most of the literature suggests only limited effects. In addition, the evidence is not always consistent. Authors who have applied more sophisticated methods have also reported limited effects, or have found virtually no effect at all.

We argue in this paper that the effects fall short of the expectations advocated by the land-use concepts, because of shortcomings behind the assumptions concerning the relationships between land use and travel behaviour. If it is assumed that people attempt to meet their basic needs within constraints of space and time, and performing trade-offs between utility and cost, it can be argued that an individual's aim is not primarily to minimise travel costs, but to maximise utility. Various behavioural responses to travel-time changes such those which can be expected in compact designs, are possible. First, if one just aims to minimise travel time, shorter distances will reduce travel times, and also, trip frequency may be decreased because trip chaining is more likely with shorter distances. As a consequence, compact urban designs offer the opportunity to travel less. Second, a fact which is often ignored is that compact urbanisation may result in people choosing more remote destinations. However, we argue in this paper that people perform trade-offs between the benefits of an activity (such as the variety or prices in a supermarket) and cost, so that travel-time savings may be exchanged for additional utlity - such as a cheaper shop further away. Third, the fact that people may make more trips if distances are shorter is also often ignored. We argue that, following the constraints-based approach, people not only maximise utility per trip, but also attempt to optimise their whole activity pattern. Travel-time savings can be used to provide time for lower priority activities (including travel) that could not otherwise take place. Fourth, travel times may also change the relative cost of each mode, and thus also influence modal choice. Artificially extended distances for cars, and reduced car speeds in pedestrian-friendly and bicycle-friendly designs, will extend car-travel times - which makes walking and cycle travel relatively more attractive. 
Hence, shorter distances and reduced car speeds encourage people to walk or cycle, rather than use cars.

To conclude, the contribution of compact urban designs to travel reduction may not be as straightforward as is suggested by its advocates. From a theoretical point of view, mode shifts due to slow mode friendly designs contribute more to sustainable travel patterns than do merely denser cities.

Nevertheless, because the spatial structure forms the context within which people travel, land-use policies still offer some potential for influencing travel behaviour. However, as society becomes more complex - including developments such as multiple car ownership per household, double-income families, telecommuting, and population ageing - the relationships between urban form and travel behaviour are also likely to become more complex. In addition, travel-demand measures are becoming more complex, which adds to the complexity of the relationships between urban form and travel behaviour. As a consequence, land-use strategies (and research in this area) need to take into account both individual and household activity and travel decisionmaking. A simple distance-oriented and trip-oriented approach cannot examine complex behaviour: on the contrary, such strategies need an approach that takes into account human behaviour in a broader framework of space and time.

Finally, it should be noted that in this paper we have considered only the effects of planning and design concepts from the perspective of travel behaviour. To determine the desirability of such concepts, more aspects need to be included in the considerations - including residential preferences, congestion, safety, and financial aspects.

\section{References}

Axhausen K W, Gärling T, 1992, "Activity-based approaches to travel analysis: conceptual frameworks, models and research problems" Transport Reviews 12 324-341

Bagley M N, Mokhtarian P, 2002, "The impact of residential neighborhood type on travel behavior: a structural equations modeling approach" Annals of Regional Science 36279 - 297

Baht C R, Koppelman F S, 1999, "A retrospective and prospective survey of time-use research" Transportation $26119-139$

Banister D, 1997, "Reducing the need to travel" Environment and Planning B: Planning and Design $24437-449$

Banister D, 2002 Transport Planning (Spon, London)

Boarnet M G, Crane R, 2001 Travel by Design. The Influence of Urban Form on Travel (Oxford University Press, New York)

Boarnet M G, Sarmiento S, 1998, "Can land-use policy really affect travel behaviour? A study of the link between non-work travel and land-use characteristics" Urban Studies 35 1155-1169

Calthorpe P, 1993 The Next American Metropolis: Ecology, Community, and The American Dream (Princeton Architectural Press, New York)

CEC, 1990 Green Paper on the Urban Environment communication from the Commission of the European Communities to the Council and Parliament COM(90)218, Luxembourg

CEC, 2001 European Transport Policy for 2010: Time to Decide white paper, Commission of the European Communities, Brussels

Cervero R, Kockelman K, 1997, "Travel demand and the 3Ds: density, diversity and design" Transportation Research D $2199-219$

Cervero R, Wu K-L, 1997, "Polycentrism, commuting, and residential location in the San Francisco Bay area" Environment and Planning A 29865 -886

CNU, 1998, "Charter of the new urbanism", Congress for the New Urbanism, http://www.cnu.org/cnu_reports/charter.pdf

Crane R, Crepeau R, 1998, "Does neighborhood design influence travel? A behavioral analysis of travel diary and GIS data" Transportation Research D $3225-238$

DETR, 2001 Planning Policy Guidance 13: Transport Department of the Environment, Transport and the Regions (The Stationery Office, London)

Dieleman F M, Faludi A, 1998, "Polynucleated metropolitan regions in northwest Europe: theme of the special issue" European Planning Studies 6365 - 377 
Ewing R, 1995, "Beyond density, mode choice, and single-purpose trips" Transportation Quarterly $4915-24$

Ewing R, Cervero R, 2001, "Travel and the built environment. A synthesis" Transportation Research Record number 1780, $87-114$

Frank L D, Pivo G, 1994, "Impacts of mixed use and density on utilization of three modes of travel: single-occupant vehicle, transit and walking" Transportation Research Record number 1466

Giuliano G, Small K A, 1993, "Is the journey to work explained by urban structure?" Urban Studies $301485-1500$

Golob T F, 1998, "A model of household choice of activity participation and mobility", in Theoretical Foundations of Travel Choice Modeling Eds T Gärling, T Laitila, K Westin (Pergamon Press, Oxford) pp $365-398$

Golob T F, 2000, "A simultaneous model of household activity participation and trip chain generation" Transportation Research B 34355 - 376

Gonzales R M, 1997, “The value of time: a theoretical review" Transport Reviews 17 245-266

Goodwin P B, 1996, "Empirical evidence on induced traffic. A review and synthesis" Transportation $2335-54$

Hägerstrand T, 1970, "What about people in regional science?" Papers of the Regional Science Association 24 7-21

Hamilton B W, 1982, "Wasteful commuting” Journal of Political Economy 901035 - 1053

Hamilton B W, 1989, "Wasteful commuting again" Journal of Political Economy 971497 - 1504

Handy S, 1996, "Methodologies for exploring the link between urban form and travel behavior" Transportation Research D 1151 - 165

Handy S L, Clifton K J, 2001, "Local shopping as a strategy for reducing automobile travel" Transportation 28317 - 346

Katz P, 1994 The New Urbanism: Toward An Architecture of Community (McGraw-Hill, New York)

Kitamura R, Mokhtarian P L, Laidet L, 1997, "A micro-analysis of land use and travel in five neighborhoods in the San Francisco Bay Area" Transportation 24 125-158

Kraan M, 1998, "In search limits to mobility growth with a model for the allocation of time and money", in Theoretical Foundations of Travel Choice Modeling Eds T Gärling, T Laitila, K Westin (Pergamon Press, Oxford) pp 89-116

Maat K, 2001, "Effects of the Dutch compact city policy on travel behaviour", in Transport and Environment: In Search of Sustainable Solutions Eds E T Verhoef, E Feitelson (Edward Elgar, Cheltenham, Glos) pp $208-230$

Meurs H, Haaijer R, 2001, "Spatial structure and mobility" Transportation Research D 6429 - 446

Ministry of VROM, 1991 Fourth Report on Spatial Planning Extra Ministry of Housing, Spatial Planning and the Environment (Sdu Uitgevers, The Hague)

Ministry of VROM, 2004 Nota Ruimte [National Spatial Strategy] Ministry of Housing, Spatial Planning and the Environment, The Hague

Modarres A, 2003, "Polycentricity and transit service" Transportation Research A $37841-864$

NæssP, Sandberg S L, 1996, "Workplace location, modal split and energy use for commuting trips" Urban Studies $33557-580$

Newman P W G, Kenworthy J R, 1989, "Gasoline consumption and cities. A comparison of US cities with a global survey" Journal of the American Planning Association 5524 - 37

Pas E I, 1998, "Time in travel choice modeling: from relative obscurity to center stage", in Theoretical Foundations of Travel Choice Modeling Eds T Gärling, T Laitila, K Westin (Pergamon Press, Oxford) pp $231-250$

Redmond L P, Mokhtarian P, 2001, "The positive utility of the commute: modeling ideal commute time and relative desired commute amount" Transportation 28 179-205

Schafer A, Victor D G, 2000, "The future mobility of the world population" Transportation Research A $34171-205$

Schwanen T, 2003 Spatial Variations in Travel Behavior and Time Use: The Role of Urban Form and Socio-demographic Factors in Individuals' Travel and Activity Patterns in the Netherlands $\mathrm{PhD}$ thesis, Utrecht University, Utrecht

Snellen D, Borgers A, Timmermans H, 2002, "Urban form, road network type, and mode choice for frequently conducted activities: a multilevel analysis using quasi-experimental design data" Environment and Planning A $341207-1220$

Stead D, 2001, "Relationships between land use, socioeconomic factors, and travel patterns in Britain" Environment and Planning B: Planning and Design 28 499-528 
Stead D, Marshall S, 2001, "The relationships between urban form and travel patterns: an international review and evaluation" European Journal of Transport and Infrastructure Research $1113-141$

Timmermans H, 2000, "Theories and models of activity patterns", in ALBATROSS: A Learning Based Transportation Oriented Simulation System Eds T Arentze, H Timmermans (Technical University, Eindhoven) pp 6-70

van Wee B, Maat K, 2004, "Land-use and transport: a review and discussion of Dutch research" European Journal of Transport and Infrastructure Research 3 199-218

van Wee B, Rietveld P, Meurs H, 2001, "Constant tijdbudget voor reizen? Mogelijke oorzaken voor een toename van de gemiddelde tijdbesteding voor reizen" [Constant time budget for travel? Possible causes of an increase in the average time spent travelling] Tijdschrift Vervoerswetenschap 3732 - 37; forthcoming in English

van Wee B, Holwerda H, van Baren R, 2002, "Preferences for modes, residential location and travel behaviour: the relevance for land-use impacts on mobility" European Journal of Transport and Infrastructure Research $2305-316$

White M J, 1988, "Urban commuting journeys are not 'wasteful'” Journal of Political Economy $961097-1110$

Zahavi A, 1979 The UMOT Project US Ministry of Transport, Washington, DC 